\title{
Ion-selective Response of the Azacrown-terminated Self-assembled Monolayer Formed on a Gold Electrode
}

\author{
Kô TAKEHARA, ${ }^{*}$ Fumihiko MUKAE, and Hiroyuki TAKEMURA \\ Department of Chemistry, Faculty of Science, Kyushu University (4-2-1, Ropponmatsu, Fukuoka, 810-8560 Japan)
}

Received November 16, 1998 ; Accepted December 21, 1998

\begin{abstract}
Thiol derivatized aza-15-crown-5-ether (15C5) was synthesized and modified on a gold electrode surface as the self-assembled monolayer. The effects of the alkali metal ions on the CV response of the $\mathrm{Fe}(\mathrm{CN})_{6}{ }^{3-}$ probe ion at the modified electrode were investigated with changing alkali metal ion. The CV response was decreased in the order of $\mathrm{Rb}^{+} \geq \mathrm{K}^{+}>\mathrm{Li}^{+} \gg \mathrm{Na}^{+}$. The results are discussed in relation to the interaction between the crown ring and the alkali metal ions.
\end{abstract}

Key Words : Self-assembled Monolayer, Ion-selective Response, Azacrown

\section{Introduction}

The fabrication of an electrode surface with selfassembled monolayer has been of considerable attention in relation to the preparation of the functional electrode surface. ${ }^{1-4)}$ By introducing thiol units to functional molecules, it is able to add various functionalities on a gold electrode by using the affinity of a thiol unit to a gold surface..$^{5-7)}$

As for the analytical application of the functional monolayer assembly, the use of size-selective molecular interaction is one of the most attracting aspects for the recognition of molecules or ions. ${ }^{8,9)}$ In this relation, Chailapakul and Crooks reported the preparation of mixed monolayer assemblies having nanoporous surface which can be utilized for sizeselective molecular recognition. ${ }^{10}$ Van Velzen et al. reported the monolayer of thiol-derivatized resorcin4 -arenes which can also be applicable for sizeselective sensor. ${ }^{11}$

In this paper, we report the electrochemical response of the $\mathrm{Fe}(\mathrm{CN})_{6}{ }^{3-}$ probe ion at the gold electrode modified with the mixed monolayer of macro cyclic N-(6-mercaptohexanoyl)-1-aza-15-crown-5-ether (15C5) and 2-mercaptoethanol (ME). The effect of the co-existing alkali metal ions on the voltammetric response of the probe ion was discussed in connection with the interaction between $15 \mathrm{C} 5$ macro cycle and alkali ions. The packing state of the modified monolayer is also discussed based on the differential capacitance measurements.

\section{Experimental}

N-(6-Mercaptohexanoyl)-1-aza-15-crown-5-ether
(15C5) was synthesized in the following way. Reaction of 1-aza-15-crown-5-ether , 6-bromohexanoyl chloride and triethylamine in ether gave $\mathrm{N}$-(6-bromo1-hexanoyl)-1-aza-15-crown-5-ether, which was successively treated with thiourea in heated water to obtain 15C5. The structure of the final product (Scheme 1) was confirmed by ${ }^{1} \mathrm{H}-\mathrm{NMR}$ (JOEL GSX270, $270 \mathrm{MHz}$ ) and IR (JASCO FT/IR-420). All organic chemicals used for the synthesis were purchased from Tokyo Kasei Co. and used as supplied. All inorganic chemicals were of analytical reagent grade and used without further purification.

Cyclic voltammetric (CV) measurements were carried out using a Fuso HECS 972 potentiostat with a HECS $321 \mathrm{~B}$ potential sweep unit in a three-electrode cell consisting of a monolayer modified working electrode, a $\mathrm{Ag}|\mathrm{AgCl}| 3 \mathrm{M} \mathrm{NaCl}$ reference electrode (BAS Inc.) and a Pt-wire counter electrode. The aqueous electrolyte solution containing $1.0 \mathrm{mM}$ $\mathrm{K}_{3} \mathrm{Fe}(\mathrm{CN})_{6}$ and $0.1 \mathrm{M} \mathrm{MCl}\left(\mathrm{M}=\mathrm{Li}^{+}, \mathrm{Na}^{+}, \mathrm{K}^{+}\right.$, or $\left.\mathrm{Rb}^{+}\right)$ was used as the test solution. The $\mathrm{CV}$ responses were recorded after the $10 \mathrm{~min}$ of the pre-scans of the potential. To monitor the formation of the monolayer, a.c. impedance measurement was performed in aqueous $0.1 \mathrm{M} \mathrm{MCl}$ solution with a Hokuto

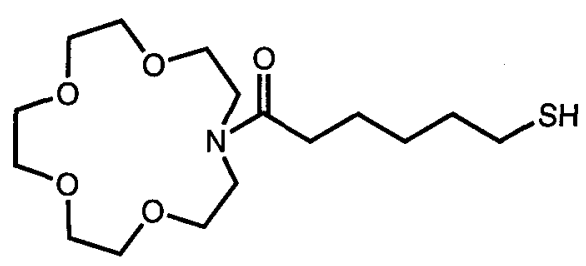

(6-mercaptohexanoyl)-aza-15-crown-5, 15C5 
Denko HA-301 potentiostat and a NF Electronic 5020 frequency response analyzer. A well polished gold disk (BAS Inc., $1.6 \mathrm{~mm}$ diameter) and a goldevaporated slide glass ( $150 \mathrm{~nm}$ thickness gold on 50 $\mathrm{nm}$ chromium adhesion layer, geometrical area of $0.502 \mathrm{~cm}^{2}$ ) were used as the working electrodes for the $\mathrm{CV}$ and impedance measurements, respectively.

The modification of monolayer on a gold electrode was performed as follows. A gold electrode was immersed in ethanolic solution of the either of $10 \mathrm{mM}$ $15 \mathrm{C} 5$ or of the mixture of $3.3 \mathrm{mM} 15 \mathrm{C} 5$ and $6.6 \mathrm{mM}$ 2-mercaptoethanol (ME) for $60 \mathrm{~min}$ (these electrodes are, henceforth, abbreviated as $15 \mathrm{C} 5 / \mathrm{Au}$ and $15 \mathrm{C} 5$ $\mathrm{ME} / \mathrm{Au}$, respectively). After this treatment, the electrode was successively rinsed with ethanol and distilled water just prior to the measurements. All measurements were carried out at room temperature and repeated at least three times to confirm the reproducibility of the responses.

\section{Results and Discussion}

Figure 1 shows the $\mathrm{CVs}$ of $1.0 \mathrm{mM} \mathrm{Fe}(\mathrm{CN})_{6}{ }^{3-}$ probe ion in $0.1 \mathrm{M}$ aqueous alkali ions observed using the $15 \mathrm{C} 5-\mathrm{ME} / \mathrm{Au}$ working electrode. Figure 1 also shows the $\mathrm{CV}$ of $\mathrm{Fe}(\mathrm{CN})_{6}{ }^{3-}$ in $0.1 \mathrm{M} \mathrm{NaCl}$ solution observed using a bare $\mathrm{Au}$ electrode. As apparent from these $\mathrm{CVs}$, the modification of the mixed monolayer of $15 \mathrm{C} 5$ and $\mathrm{ME}$ decreased the redox peak of $\mathrm{Fe}(\mathrm{CN})_{6}{ }^{3-}$ especially the cathodic peak of the response. Moreover, the extent of the peak decrease depends on the kind of the alkali metal ions. $\mathrm{Na}^{+}$ion most effectively suppressed the cathodic peak of $\mathrm{Fe}(\mathrm{CN})_{6}{ }^{3-}$ and the effect was reduced in the order of $\mathrm{Na}^{+} \gg \mathrm{Li}^{+}>\mathrm{Rb}^{+} \geq \mathrm{K}^{+}$.

It is known that $\mathrm{Na}^{+}$preferably form the $1: 1$ complexes with 15-crown-5 derivatives including aza15-crown-5. ${ }^{12,13)}$ It was also reported the selective complex formation of a 15-crown-5 ring with $\mathrm{Li}^{+}$ion,

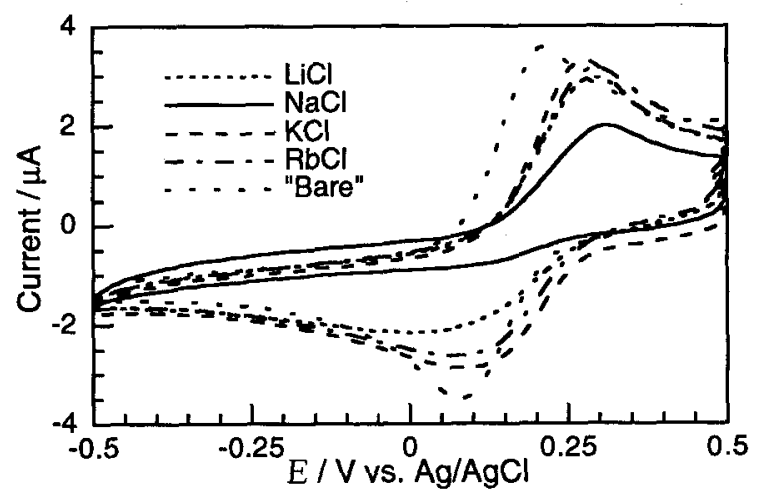

Fig. $1 \mathrm{CVs}$ of $1.0 \mathrm{mM} \mathrm{K}_{3} \mathrm{Fe}(\mathrm{CN})_{6}$ in $0.1 \mathrm{M} \mathrm{MCl}(\mathrm{M}=\mathrm{Li}$, $\mathrm{Na}, \mathrm{K}$ and $\mathrm{Rb}$ ) aqueous solution observed at $15 \mathrm{C} 5-\mathrm{ME} / \mathrm{Au}$ electrode and in $0.1 \mathrm{M} \mathrm{NaCl}$ observed at bare $\mathrm{Au}$ electrode. Scan rate was $100 \mathrm{mV} \mathrm{sec}{ }^{-1}$. by introducing the side-arm unit to the ring. ${ }^{14)}$ In the cases of $\mathrm{Rb}^{+}$and $\mathrm{K}^{+}$ions, in contrast, it seems to hard to form the $1: 1$ complexes with 15 -crown- 5 ring by considering these ion sizes and the cavity size of the ring. By taking into account above discussions, it is reasonable to consider that the suppress of the $\mathrm{CV}$ peak is caused by the complex formation of the $15 \mathrm{C} 5$ ring with alkali ion and the order of $\mathrm{Na}^{+} \gg \mathrm{Li}^{+}>\mathrm{Rb}^{+}$ $\geq \mathrm{K}^{+}$is reflected by the stability of the complexes.

As shown in Fig. 2, when the gold electrode was modified only with $15 \mathrm{C} 5(15 \mathrm{C} 5 / \mathrm{Au})$, no redox peak of the $\mathrm{Fe}(\mathrm{CN})_{6}{ }^{3-}$ probe was observed for the all of alkali ions examined. This result indicates that the modified 15C5 monolayer effectively hinders the $\mathrm{Fe}(\mathrm{CN})_{6}{ }^{3-}$ electrode process, independent on the alkali ions. In the case of $15 \mathrm{C} 5-\mathrm{ME} / \mathrm{Au}, \mathrm{co}$-adsorbed $\mathrm{ME}$ molecules decrease the packing density of the $15 \mathrm{C} 5$ molecules. Such a loosely packed state of the monolayer will enable the electrochemical communication between the Au surface and $\mathrm{Fe}(\mathrm{CN})_{6}{ }^{3-}$ ion even if the $\mathrm{Fe}(\mathrm{CN})_{6}{ }^{3-}$ ion does not closely approach to the $\mathrm{Au}$ surface. In this situation, the extent of the electrochemical communication is expected to be affected by the change of the monolayer condition caused by the complex formation of the $15 \mathrm{C} 5$ ring with alkali ion. In the case of $15 \mathrm{C} 5 / \mathrm{Au}$, in contrast, densely packed $15 \mathrm{C} 5$ monolayer will hinder the electrochemical communication between the Au surface and $\mathrm{Fe}(\mathrm{CN})_{6}{ }^{3-}$ ion, independent on the complex formation of the monolayer.

To clarify the difference of the monolayer conditions between $15 \mathrm{C} 5-\mathrm{ME} / \mathrm{Au}$ and $15 \mathrm{C} 5 / \mathrm{Au}$, the differential capacitance values $\left(C_{d}\right)$ of these electrodes in $0.1 \mathrm{M} \mathrm{NaCl}$ and $0.1 \mathrm{M} \mathrm{KCl}$ were estimated by using a.c. impedance technique. Figure 3-a and Fig. 3-b show the Cole-Cole plots of the complex admittance values in $0.1 \mathrm{M} \mathrm{NaCl}$ and in $0.1 \mathrm{M} \mathrm{KCl}$, respectively. Table 1 listed the $C_{d}$ values calculated from hemi-

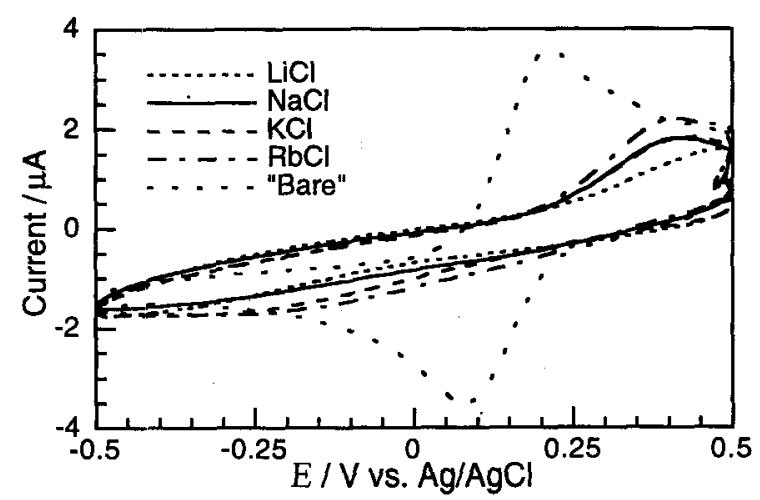

Fig. $2 \mathrm{CVs}$ of $1.0 \mathrm{mM} \mathrm{K}_{3} \mathrm{Fe}(\mathrm{CN})_{6}$ in $0.1 \mathrm{M} \mathrm{MCl}(\mathrm{M}=\mathrm{Li}$, $\mathrm{Na}, \mathrm{K}$ and $\mathrm{Rb}$ ) aqueous solution observed at $15 \mathrm{C} 5 / \mathrm{Au}$ electrode and in $0.1 \mathrm{M} \mathrm{NaCl}$ observed at bare $\mathrm{Au}$ electrode. Scan rate was $100 \mathrm{mV} \mathrm{sec}{ }^{-1}$. 
circle fitting of the complex admittance plots. It is apparent from the results that the $C_{d}$ value decreased in the order of bare $\mathrm{Au}>15 \mathrm{C} 5-\mathrm{ME} / \mathrm{Au}>15 \mathrm{C} 5 / \mathrm{Au}$. As reported by Porter et al., $C_{d}$ value is inversely proportional to the monolayer thickness which hinders the close approach of ionic species in solution to the gold surface. ${ }^{1)}$ Therefore, it is reasonable to consider that the $15 \mathrm{C} 5$ monolayer is more densely packed than 15C5-ME monolayer and effectively hinders the permeation of ionic species. More importantly, there are no significant difference between the $C_{d}$ values in $0.1 \mathrm{M} \mathrm{NaCl}$ and in $0.1 \mathrm{M} \mathrm{KCl}$ solutions in spite of the clear difference of the $\mathrm{CV}$ response at $15 \mathrm{C} 5 \mathrm{-ME} / \mathrm{Au}$. Although there are no clear explanation for this result, one possibility is that the interaction between alkali ion and monolayer occurs only at the very surface of the monolayer, that is at the terminally anchored $15 \mathrm{C} 5$ ring. Therefore, the inter-
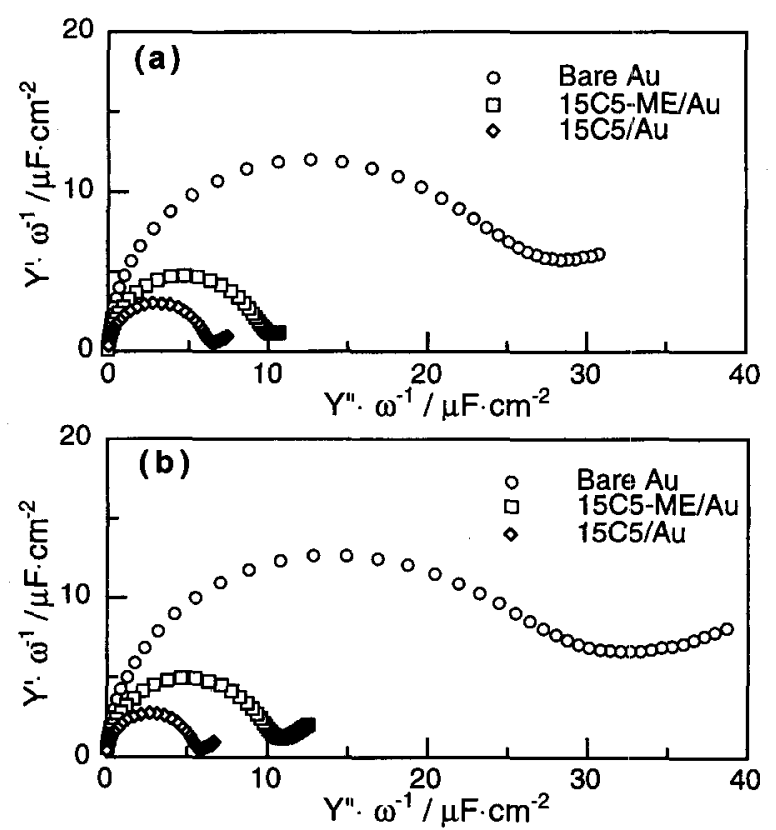

Fig. 3 Cole-Cole plot of the complex admittance observed in (a) $0.1 \mathrm{M} \mathrm{NaCl}$ and (b) $0.1 \mathrm{M} \mathrm{KCl}$. The working electrodes used were bare $\mathrm{Au}, 15 \mathrm{C} 5 \mathrm{-ME} / \mathrm{Au}$ and $15 \mathrm{C} 5 / \mathrm{Au}$, as indicated in the figure. A.c. amplitude and frequency range were $10 \mathrm{mV}(\mathrm{RMS})$ and $1.0 \mathrm{~Hz}-10 \mathrm{kHz}$, respectively, and the applied d.c. potential was $0.0 \mathrm{~V}$ vs. $\mathrm{Ag}|\mathrm{AgCl}| 3 \mathrm{M}$ $\mathrm{NaCl}$ reference electrode.

Table 1 Differential capacitances, $C_{d}$, calculated by hemicircle fitting.

\begin{tabular}{|l|c|c|}
\hline \multicolumn{1}{|c|}{ Electrode type } & $C_{d} / \mu \mathrm{F} \mathrm{cm}^{-2}$ \\
\hline & $0.1 \mathrm{M} \mathrm{NaCl}$ & $0.1 \mathrm{M} \mathrm{KCl}$ \\
\hline Bare $\mathrm{Au}$ & 12.2 & 14.1 \\
\hline $15 \mathrm{C} 5-\mathrm{ME} / \mathrm{Au}$ & 4.8 & 5.2 \\
\hline $15 \mathrm{C} 5 / \mathrm{Au}$ & 3.1 & 2.8 \\
\hline
\end{tabular}

action does not affects the alkyl chain layer of the monolayer which mainly contributes to the characteristics of the differential capacity.

In conclusion, thiol derivatized aza-15-crown-5ether was synthesized and its self-assembled monolayer was formed on a gold electrode surface. The effect of the co-existing alkali metal ions on the redox response of the $\mathrm{Fe}(\mathrm{CN})_{6}{ }^{3-}$ probe ion at the $15 \mathrm{C} 5$ modified gold electrode was investigated by using cyclic voltammetry. The $\mathrm{CV}$ response of a $\mathrm{Fe}(\mathrm{CN})_{6}{ }^{3-}$ probe ion decreased in the order $\mathrm{Rb}^{+} \geq$ $\mathrm{K}^{+}>\mathrm{Li}^{+} \gg \mathrm{Na}^{+}$. This order is inversely proportional to the interaction strength between $15 \mathrm{C} 5$ and alkali ions which is expected from these ion sizes and the ring size of the $15 \mathrm{C} 5$. The differential capacitance measurement made clear the difference of the monolayer packing states between 15C5-ME/Au and $15 \mathrm{C} 5 / \mathrm{Au}$.

\section{Acknowledgment}

This work was financially supported by Tokuyama Science Foundation and by a Grant-in-Aid for Scientific Research (09640691) from the Japan Ministry of Education, Science, Sports and Culture to whom we are grateful.

\section{References}

1) M. D. Porter, T. B. Bright, D. L. Allara, and C. E. D. Chidsey, J. Am. Chem. Soc., 109, 3559 (1987).

2) C. E. D. Chidsey, C. R. Bertozzi, T. M. Putvinski, and A. M. Mujsce, J. Am. Chem. Soc., 112, 4301 (1990).

3) C. Miller, P. Cuendet, and M. Graetzel, J. Phys. Chem., 95, 877 (1991).

4) S. Steinberg, Y. Tor, E. Sabatani, and I. Rubinstein, J. Am. Chem. Soc., 113, 5176 (1991).

5) W. Itamar, R. Blonder, and A. Dagan, J. Am. Chem. Soc., 116, 9365 (1993).

6) M. T. Sharon, B. D. Iddo, and W. Itamar, J. Am. Chem. Soc., 118, 4717 (1996).

7) J. Madoz, B. A. Kuznetzov, F. J. Medrane, J. L. Garcia, and V. M. Fernandez, J. Am. Chem. Soc., 119, 1043 (1997).

8) H. Schöherr and J. G. Vancso, Langmuir, 13, 1567 (1997).

9) H. Ju and D. Leech, Langmuir, 14, 300 (1998).

10) O. Chailapakul and R. M. Crooks, Langmuir, 9, 884 (1993).

11) E. U. T. van Velzen, J. Am. Chem. Soc., 116, 3597 (1994).

12) J. M. Lehn and J. P. Sauvage, J. Am. Chem. Soc., 97, 6700 (1975).

13) H. Tshukube, T. Inoue, and K. Hori, J. Org. Chem., 59, 8047 (1994).

14) H. Takeshita, Q. F. Wang, K. Kubo, and A. Mori, Chem. Lett., 993 (1995). 